\title{
Anatomy of lumbosacral spinal nerve roots
}

\author{
Domenico d'Avella $\cdot$ Luca Denaro
}

Received: 8 February 2015 / Accepted: 11 February 2015/Published online: 15 March 2015

(C) Springer-Verlag Wien 2015

Dear Editor,

We would like to compliment Dr. Kirazh and colleagues on their recent detailed morphological study of the spinal dorsal root entry zone [Kirazh Ö, Tatarli N, Güçlü B, Ceylan D, Ziyal İ, Keleş E, Çavdar S (2014) Acta Neurochir 156: 2351-2358].

They reported on the variations of the posterolateral sulcus, including the average number of rootlets at each spinal level, emphasising their microsurgical implications, especially for DREZ operations.

In their observations, the number of dorsal rootlets at the lumbar level ranged between four and eight, the number of rootlets was lowest at L5, and the rest of the lumbar levels were rather constant. The authors stated they "could not find any study to compare our results at the lumbar level".

We would like to bring to the readers' attention that this study extends and completes our previous microsurgical work [1] on lumbosacral spinal roots, describing the microanatomy of the entry zone of the posterior and anterior roots into the spinal cord and the occurrence of intrathecal anastomoses between the dorsal and ventral roots.

Thus, these two reports mutually contribute to the understanding that the posterolateral sulcus does not exhibit a constant anatomical pattern and that a variety of interconnections may occur between the afferent lumbosacral spinal nerve roots, so the spinal cord is made up of a series of neuromeres overlapping to some extent.

We emphasise that knowledge of these variations is important for achieving successful surgeries in this region.

\section{Reference}

1. d'Avella D, Mingrino S (1979) Microsurgical anatomy of lumbosacral spinal roots. J Neurosurg 51:819-823
D. d'Avella $(\bowtie) \cdot$ L. Denaro

Department of Neurosciences, Academic Neurosurgery, University

of Padova, Via Giustiniani 2, 35128 Padova, Italy

e-mail: domenico.davella@unipd.it 